\title{
Impact of different health educational modalities in screening for cervical cancer in selected areas of Chennai, India.
}

\author{
Dr. ShyamalaDeviManivannan \\ $R N ., R M ., M S c .,(N) P h D .,(N)$ \\ Principal, M.A.Chidambaram College of nursing, The TamilNaduDr.MGR Medical university, India
}

\begin{abstract}
Cancer of the cervix is acknowledged as the leading cancer of women in India. Pap smear screening is known to be very effective in secondary prevention but women lack awareness. The focus of primary prevention has been health education and we need to stress on this using various means to motivate women undergo pap smear test.

Objectives: This study aim to explore husbands' awareness on wives' reproductive related symptoms leading to cervical cancer if not treated on time, the impact of including men in the process of motivating women for pap smears and the better working methods for health educating women to come for cervical pap smear tests.

Methods: The survey technique was used to collect the baseline information and for issuing the pamphlets and quasi experimental design was used for conducting the second part of the study.Betty Newmans' sytems theory was used for conceptualization of the study.

Results: Husbands found to be unaware of the reproductive tract related sickness symptoms. re Health educating only husbands could get 5 times more the response than motivating only wives. Educating couples get 10 times more the response than motivating only wives. Reinforced teaching has better success rates.

Conclusions Including husbands at all points of wives education would yield better results. Women need to discuss their sickness symptoms with their husbands. Government policies need to be laid down to adopt these practices on a routine basis.
\end{abstract}

Key words Husbands, wives, pap smear, pamphlets, health education, cervical cancer, primary prevention, working, methods, motivating

\section{Introduction}

Cancer of uterine cervix is the most commonly found cancer among rural Indian women. Early marriage, early coitus, too many deliveries, too close deliveries, multiple partners, poor hygiene, illiteracy and ignorance are noted predisposing factors for cancer cervix. Three quarters of India's population living in rural areas where measures of health and living standards are low, rural women are vulnerable to develop cervical cancer. Health education and pap smear screening are considered as important part of the primary and secondary preventive measures for stopping the deaths from cervical cancer.

Population based cancer registries of India highlighted that the cancer of the uterine cervix was the top ranking cancer among females (2001,UshaLuthra and Jain)[1]. Even when combined ranking was done among both the sexes, cancer cervix had taken the first place during the year 1999-2001. The average number of new cases per year was 543 for the year 2001 constituting about $25 \%$ of all female cancers.

\section{Background}

International agency for cancer research (1997)[2] report showed an estimated annual global incidence of 500,000 cervical cancer and India contributes 108,000 that equal 1/5 of the world's burden of cervical cancer.According to Nandakumar, Anantha and Venugopal (1995) [3]100,000 new cases of cancer cervix occur in India every year and 70\% or more of them are in stage III or higher at diagnosis. Bang et al (1991) conducted a study in rural, tribal areas of Maharastra, India, indicates that $92 \%$ of the women suffered from one or more gynecological problems and that the majority had never sought any treatment.[4]

Mishra and Sinha (1990) stated that there is an association between reproductive tract infection and cervical cancer.[5] Baroda citizens council (1997) conducted four community-based studies of gynecological morbidity in four different sites of India (rural west Bengal, Gujarat, urban Baroda and Bombay). They reported the prevalence of clinically diagnosed Reproductive Tract Infections (RTIs) as 19 to 71 percent. [6] Bhatia,J.C.,Cleland.L.,Bhagwan.,Rao,N.S.N. (1997) found that in rural Karnataka over 70 percent of women had clinical or laboratory evidence of RTIs.

Pachauri (1996) indicated that the prevalence of RTIs in India is unacceptably high and that gynecological morbidity constitutes a major public health problem among poor women. These reproductive problems are invisible because of socio-cultural reasons and are unattended because women do not have access to health care for these illnesses. [7] 
Vivilaki,V., Romanidou,A., Theodarakic,P., Lionis,C. (2005) organized a health education meeting in a center for elderly to promote cervical screening. Following this the participants were asked to visit primary health care center within 15 days in order to get screened. This encouraged the participant to undergo the pap smear procedure. The participant also realized the social responsibility of the individual and brought an additional 32 women to participate in the program.[8]Tseng,D.S., Cox,E., Plane, M.B., Hla,K.M(2001) investigated the impact of patient letter reminders on improving the numbers screened for cervical cancer. Patient reminders in the form of mailed letters increased the rate of cervical cancer screening. [9]

Rezaei,M.B., Seydi,S., Alizadeh,S.M. (2004) studied the effects of two educational methods on knowledge attitude and practices of 129 female teachers in east Azarbaijan, Iran. [10] Education by lecture and flash cards was more effective than by pamphlets. In regard to Pap smear practice, there was a significant difference between the 2 experimental groups as compared with the control group, but there was no significant difference between 2 experimental groups. The educational methods were effective on knowledge, attitude and practice of teachers regarding prevention of cervical cancer and education by lecture and flash cards was more effective than by pamphlets in increasing knowledge and inducing a positive attitude towards pap smear tests.

In India there was not much research work carried out by doctoral level nurses on cervical cancer, the silent killer of women if it is not diagnosed in its early stages. Nurses need to involve more and more in knowing the problems of the community, and help women in knowing and communicating the disease symptoms without any hesitancy.

By doing extensive literature review the investigator learned that cancers of the reproductive tract have received little attention even though these increasingly contribute to reproductive morbidity and mortality. Cancer of the cervix is acknowledged as the leading cancer of women in India. Pap smear screening is known to be very effective in the secondary prevention of the disease. Yet there are significant obstacles for applying this knowledge to control the disease in India. The focus on primary prevention has been health education and we need to stress more on this.

The surveys that have performed have shown that the Indian women are ignorant on the importance of knowing the disease and the risk factors of the disease.. Many women plan their hospital visits based on their husband's affordability and decision. Woman values husband and children more than she values herself. Even after crossing all these boundaries women are very much fearful about any pelvic related procedures.

\section{Methods}

To collect baseline information and for issue of the pamphlets the survey technique was used. Investigator enrolled only the women who were married and living with the husbands because the study's major portion was stressing to know whether the inclusion of husbands have any impact in motivating wives to come for cervical pap smear test. To enroll the participants directly there were no suitable existing records which could meet the study criteria. At this juncture the investigator was guided by the expert epidemiologist to choose survey technique to initiate the study.

The investigator had used quasi experimental design for conducting the second part of the study. Since the survey technique is the non-experimental design which could not meet the equirements of the second part of the study, the quasi experimental design was chosen. This study had the limitation of including the married women who are living with their husbands. Only control and intervention were used in assessing the impact of reinforced teaching over the mere issue of pamphlets. So the quasi experimental design was used for conducting the second part of the study. This study was carried out in selected villages of Chennai, India. Villages were selected using simple random sampling technique.

A total of four villages chosen; Three were considered as experimental areas and the fourth one was assigned to be the control area. In village -1 , couple were delivered health education using flash cards on cervical cancer; in village- 2 , only the husbands were given health education and in village three only the wives were health educated; before the health education couples were interviewed separately to know the certain demographic variables and reproductive tract related symptoms in their wives.

In all these three villages pamphlets were issued initially to the concerned people as a calling measure to attend planned health education in the centers. Couples were interviewed separately as they arrived in the center for health education. After the health educational sessions pap smears were done for the women who came forward on their own or brought by her husband. In village four, the control area, only pamphlets were issued to all the households to attend health education. A total of 600 couples who met the study criteria, were considered as the sample size of this study. This sample was drawn from the enrolled number of 1118 in experimental area. Totally 382 couples who met the eligibility criteria were issued pamphlets in the control area.

Non-probability purposive sampling technique used to select the samples of the study. By using survey, the couples living together were only enrolled in this study. In experimental area, wives who were motivated on importance of cervical pap smear tests by direct health education or indirect motivation through their husbands and came forward for pap smear tests were taken as samples. In control, area women motivated through pamphlet 
education and came forward for pap smears were the samples. Ethical clearance obtained from the research committee to initiate the study. Permission received from the concerned community leaders and significant ones to conduct the study. Consent of the study participants obtained as a measure to protect the human rights. No couple was compelled to enroll in the study.

\section{Results}

Overall responses of couples on presence of abdominal pain among wives in experimental group highlighted that only $166(27.7 \%)$ husbands were aware of wives abdominal pain. But, in fact $280(46.7 \%)$ wives reported that they were having constant lower abdominal pain. The difference was statistically significant. $(\mathrm{P}<0.001)$.

The overall opinions of couples about presence of excessive bleeding P.V in wives revealed that $132(22 \%)$ wives were suffering with the problem of excessive bleeding P.V. and it was known only by $79(13.2 \%)$ of the husbands.(fig.1) The highlighted difference $8.8 \%$ was found to be statistically significant.( $\mathrm{Z}=3.93, \mathrm{P}$ $<0.001)$.[fig.1]

A total of $254(43.2 \%)$ wives were having the problem of white discharge p.v; but this was known only by $123(20.5 \%)$ of the husbands. (fig.2) This had given out the large difference of $22.7 \%(17.4-27.9)$ which was found to be statistically significant. $(\mathrm{Z}=8.38, \mathrm{P}<0.001)$

In experimental area 1118 pamphlets were issued calling for pap smears. Only 75 (6.71\%) women responded and willing to undergo pap test with pamphlet education. In control area out of 382 pamphlets issued $36(9.42 \%)$ women came forward for pap smear test. This did not reveal much difference between experimental and control area. So, it shows the general kind of ignorant behavior towards distribution of pamphlets.(Table:1)

Table: 2 clearly says that if we motivate only wives we will be able to achieve $25 \%$ success, if we motivate only husbands we can achieve $60 \%$ success and if we motivate the couples we can achieve $76 \%$ success. So, if we health educate only husbands we could get 5 times more the response than motivating only wives. If we health educate couples we get 10 times more the response than motivating only the wives. This result is confirmed by chi-square for trend analysis $\left(\chi^{2}=194.7, \mathrm{P}=0.001\right)$.

Table: 3 reveals that mere issue of pamphlets in control group could motivate $36(9.4 \%)$ women to undergo cervical pap smear tests, whereas pamphlet issue and reinforced second stage of teaching by flash cards could motivate (600) $53.7 \%$ of women to undergo cervical pap smear tests. This shows significant difference between mere issue of pamphlets and pamphlet issue cum, reinforced direct teaching with flash cards.. This result was statistically significant as per Pearson chi-square test $\left(\chi^{2}=228.2, \mathrm{P}=0.001\right)$

\section{Discussion}

Cervical cancer continues to be one of the most commonly found cancer affecting the women worldwide. In the developed countries that have implemented the pap smear screening programs, the incidence of cervical cancer has markedly reduced. In developing countries the problem of undiagnosed, cervical cancer leading to mortality is increasing day by day.Many research scholars of various disciplines trying to use their innovative approaches and novel ideas in increasing cervical pap smear awareness among women to detect the disease in its early stage. Simultaneously many are trying to strengthen the primary level prevention by means of creating awareness among the women.This study revealed the fact that higher number of womennever attended school.Illiteracy is one of the factors which make women dumb in any kind of their welfare activity. "Health is wealth' concept need to be understood by the women to provide the concrete base of education. So that women can keep away many diseases by knowing the preventive measures.

This study clearly conveys the message that the rural women's educational status need to be strengthened at all levels.Cesar J.A et al (2003) quoted that the young age, low family income and low schooling as the risk factors for cervical cancer. [11] According to the present study we could say that the women who are illiterate are highly prone for developing cervical cancer because of their ignorance which is closely related to their illiteracy. This is also supported by another study by Brenna. S.M (2000).[12]

Women spend their time mostly to earn their livelihood and meet their family commitments. This makes them neglect their own health. Even when a woman herself is an earning member she spends her income only to her family. If mother and child happened to fall sick at a time, the mother values her child's health than hers. There is an established association between reproductive tract infection and cervical cancer. (Mishra and Sinha)[5] Their study highlighted and supported the findings of the present study. There are many women of rural India are found to be with one or the other gynecological infections and they do not seek treatment for the same. So these women with untreated reproductive tract infections are highly prone to develop cancer of the cervix.

The responses of couples on existing reproductive health related symptoms of the wives in experimental area showed the significant difference and it is found to be statistically significant. We can accept the first hypothesis of this study that there is difference of opinion between the couples regarding the wives health status. Issue of pamphlets could bring about $6.8 \%$ success rates among couples group $7.32 \%$ success among husbands 
group and $6.01 \%$ success among women group. There was not much difference found between the groups regarding the response showed towards pamphlets issued. So success rates seemed to be less than $7 \%$ in all the groups. This finding tells us clearly that mere issue of pamphlets could bring about $<7 \%$ success rates in calling women for pap smear tests irrespective of kind of health education group used. We do witness many organizations issuing pamphlets to educate the public. This study had revealed that the mere issue of pamphlets will not yield very good results. This was supported by the study done by Rezaei,M.B., Seydi,S., Alizadeh,S.M. (2004)[10]

After health education with flash cards 281 (88.92\%) from couples' group, 229 (87.73\%) women through educating only the husbands, 90 (70.86\%) women from (by educating the women) underwent pap smear procedures (Table 45).These findings definitely proved that the success rates were found better among couples group. This study clearly says that we need to include men / husbands when we educate the wives.Miller.A.B. et al (1992)in their study, " information on cervical cancer and the role of the male in prevention as well as in encouraging his partner to participate in screening should be communicated sufficiently early in life to have an effect." [13]

In Indian culture it is the routine practice of a woman to consult with husband and make decisions. Always husbands take a lead role in any kind of activity but there are few exceptions. But some men are not even aware about the existing health problems of their wives. Cervical cancer is also closely related with the sexual behaviors of the men. Human papilloma virus (HPV) is the causative factor for cancer cervix. HPV is prevalent among the men who have extra-marital relationships, especially those who visit the commercial sex workers. Men who have no chastity value put their wives at risk of developing cancer cervix.

As a result of pamphlet issue and flash card teaching, men came forward for attending health education and also brought out a good success rates in bringing their wives for cervical pap smear tests. Sellers T. A. et al., (2002) [14]designed a program to enhance the skills of nurses and other health service providers and develop clinic support systems to better recruit, screen and follow clients for breast and cervical cancer screening services. But there are no existing studies which had involved men in motivating women. Regular health educational sessions on "cervical cancer prevention and early detection"planned on regular base in mother and child health care out patients department will definitely yield a fruitful outcome.Motivation of wives using pamphlet cum flash card education, yields $25 \%$ success rate. If we motivate only husbands using pamphlet and flash card education we can achieve $60 \%$ success rates and if we motivate the couples we can achieve $76 \%$ success . There is a difference exist between different "health -educational target groups" in causing the awareness on cervical pap smears.

When we compared the cervical pap smear test response for mere issue of pamphlets (in control area) and pamphlet cum reinforced teaching with flash cards (in experimental area) 53.7\% of women had undergone pap test in experimental area and $9.4 \%$ had undergone pap test in control area. This had showed the statistically significant difference between both the areas. Odd's ratio shows that pamphlet cum flash card teaching is 11 times better over the mere issue of pamphlets. This finding gets along with formulated hypothesis i.e. there is a difference between issuing only pamphlets and combined educational methods.

Men are the important focus for family planning and reproductive health services, not only because they have their own concerns in this area, but also their health status and behavior affect women's reproductive health. Men can support their partners use contraception or use contraceptive methods themselves, and they can help in preventing the spread of sexually transmitted infections. Alberta (2003) cervical cancer screening programs (ACCSP) in Calgary[15] is investigating the issues related to male involvement in cervical cancer prevention-; particularly how men can support and encourage their partners to seek out screening services as well as what role men play in women's ability to follow post treatment instructions, which include the need for a short period sexual abstinence. 


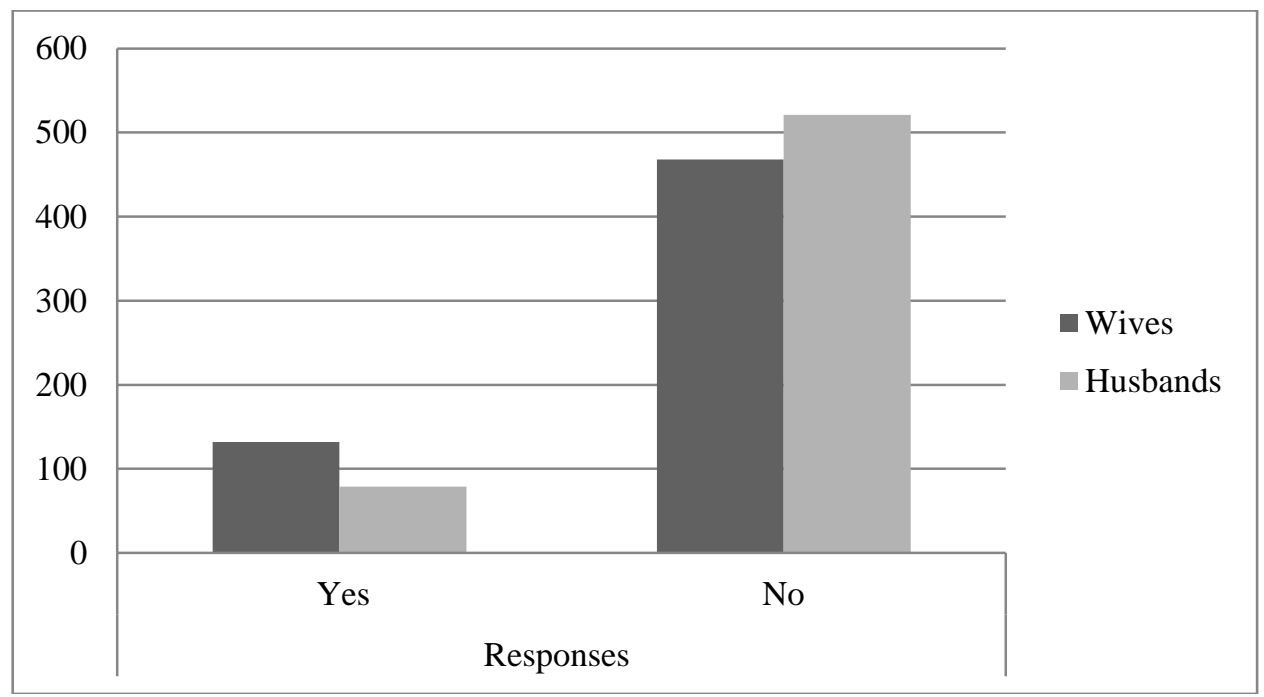

Fig.1. Differences between responses of couples' on excessive bleeding P.V.

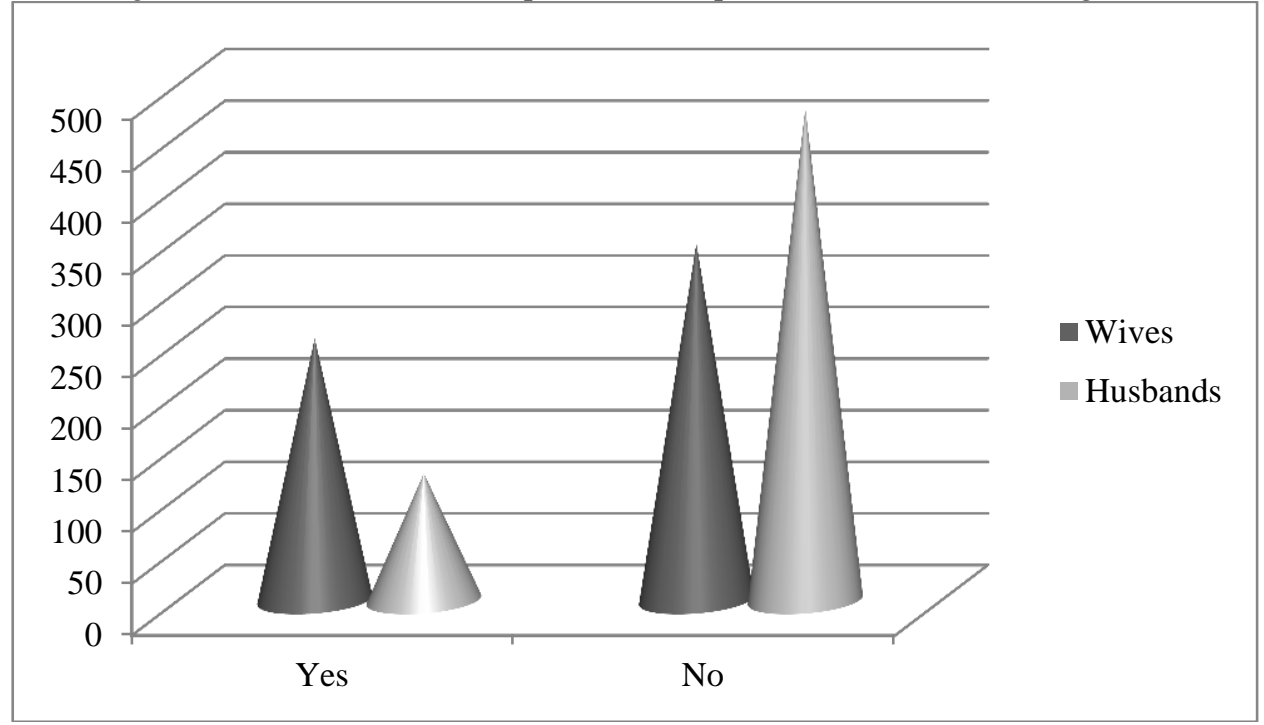

Fig.2 Differences between responses of couples on white discharge P.V

Table 1: Women Volunteered for Pap smear test As a Response ToPamphlet -Distribution

\begin{tabular}{|cccc|}
\hline Underwent Pap smear & & & \\
Group & Yes & No & Total Pamphlets issued \\
Experimental & 75 & 1043 & 1118 \\
Control & 36 & 346 & 382 \\
\hline
\end{tabular}

Table 2: Women Underwent Pap smear tests In Various Educational Target Groups After Pamphlets cum Flash card Education

\begin{tabular}{|c|c|c|c|c|}
\hline \multicolumn{5}{|c|}{ Underwent Pap smear } \\
\hline Yes & No & Total & Odd's Ratio & \\
\hline Couples & 281 & 89 & 370 & 9.7 \\
\hline Husbands & 229 & 153 & 382 & 4.6 \\
\hline Wives & 90 & 276 & 366 & 1.0 \\
\hline
\end{tabular}


Table 3: Cervical pap test response for mere issual of pamphlets and reinforced teaching with flash cards

\begin{tabular}{|c|c|c|c|}
\hline \multirow{2}{*}{$\frac{\text { Health educational }}{\text { methods }}$} & \multicolumn{2}{|c|}{ Underwent cervical pap smear } & Total \\
\hline & Yes & No & \\
\hline $\begin{array}{l}\text { Pamphlets flash card } \\
\text { teaching }\end{array}$ & 600 & 518 & 1118 \\
\hline Only pamphlets & 36 & 346 & 382 \\
\hline
\end{tabular}

$\chi^{2}=228.2, \quad \mathrm{P}=0.001 \quad$ Odds Ratio $11.13(7.6-16.3)$

Table 3: Cervical Pap test Response To Mere Issue of Pamphlets and Reinforced Teaching with flash cards

\begin{tabular}{|l|c|c|c|}
\hline Health education & \multicolumn{2}{|c|}{ Underwent cervical pap } & Total \\
\hline Smear test & No & 1118 \\
\hline $\begin{array}{l}\text { Pamphlets and flash } \\
\text { card (experimental) }\end{array}$ & 600 & 518 & 382 \\
\hline $\begin{array}{l}\text { Only } \\
\text { pamphlets(control) }\end{array}$ & 36 & 346 & \\
\hline
\end{tabular}

$\mathrm{n}=1118$ (experimental) $\mathrm{n}=346$ (control)

\section{Conclusions}

There were not much differences found between the experimental and control groups in the demographic variables which were taken into consideration. There were differences of opinion found between the couples on almost all the aspects regarding the presence of selected symptoms, which could lead to cancer cervix. This study had proved that the inclusion of husbands while health-educating women would increase the pap smear rates thereby increase the early detection of cervical cancer. Nurses could play a key role in contributing to women's health.

\section{References}

[1]. UshaLuthra, K., Jain, D.K. (2000). National cancer registry programme: Biennial report 1990- 1996 Population based cancer registries. Indian Council of Medical Research

[2]. International institute for population sciences. National family health survey (NFHS-2) 1998-99 Mumbai, India

[3]. Bang, R.A., Bang, A. (1991).women hide them: Rural women's view points on reproductive tract infections. Manushi (69) 27-30.

[4]. Mishra,M.K., Sinha,T.K., (1990). Cytological screening for the detection of cancer in the uterine cervix.A Survey in Patna (India).Cancer Cell (2)1.

[5]. Baroda Citizens council (1997) Prevalence of clinically detectable gynecological morbidity in India. Unpublished studies manuscript

[6]. Pachauri,S. (1996). Reproductive Health: Concept, Ideology and operational issues in perspective health education. New Delhi: New Age Publisher Ltd.

[7]. Vivilaki.V, Romanidon,.A., Theodorakic.P., Lionis,C. (2005). Are health education meetings effective in recruiting women in cervical screening programmes. An innovative and inexpensive intervention from the Island of Crete. Rural remote health. $5(2) 376$.

[8]. Tseng,D.S. (2001). Efficacy of patient letter reminders on cervical cancer screening, Journal of General internal medicine. (16) 563568.

[9]. Rezaei,M.B., Seydi,S., Alizadeh,S.M. (2004). Effects of two educational methods on the knowledge attitude, and practice of women high school teachers in prevention of cervical cancer. Cancer nurse. 27(5) 364-369. Cesar,J.A. (2004). Factors Associated with nonparticipation in screening for cervical cancer in Southern Brazill. Cad Saude Publication. 19(5) 1365-1372

[10]. Brenna,S.M. (2000). Knowledge attitudes and practices related to the pap smear among women with cervical cancer. Lad soarde publication. (17) 909-914.

[11]. Miller,A.B. (1992) Cervical cancer screening programme: Managerial guidelines, WHO, Geneva. 24-25

[12]. Sellers,T.A. (2002). Evaluation of a program to train nurses to screen for breast and cervical cancer among native American women. Journal of cancer education.17(1):24-27. 